\title{
The association between high-sensitivity C- reactive protein at admission and progressive motor deficits in patients with penetrating artery infarctions
}

Pengyu Gong ${ }^{1}$, Yukai Liu', Ting Huang ${ }^{1}$, Wenxiu Chen², Teng Jiang ${ }^{1}$, Yachi Gong ${ }^{3}$, Min Lu', Meng Wang ${ }^{1}$, Yingdong Zhang ${ }^{1 *+}$, Xiaohao Zhang ${ }^{4}$, Qiwen Deng ${ }^{1 *+}$ and Junshan Zhou ${ }^{1 *+}$

\begin{abstract}
Background: A fraction of patients with penetrating artery infarction (PAI) experience progressive motor deficit deterioration (PMD). We sought to investigate the role of high-sensitivity C-reactive protein (hs-CRP) at admission in predicting PMD.

Methods: From January 2015 to September 2018, consecutive patients with PAl from three centers were prospectively enrolled in this study. PMD was defined as worsening of motor function score by $\geq 1$ point on the National Institutes of Health Stroke Scale during the first 5 days after admission. Multivariable logistic regression analyses were performed to explore the relationship between hs-CRP and PMD in patients with PAI. We also performed receiver operating characteristic curve analysis and constructed a nomogram to assess the overall discriminative ability of hs-CRP in predicting PMD.

Results: We ultimately included 544 patients (mean age, $65.4 \pm 11.8$ years). A total of 85 (15.6\%) patients were identified to have PMD. Multivariate logistic regression analysis showed that hs-CRP was independently associated with PMD ( $P=0.001)$. The optimal cutoff value for hs-CRP as a predictor for PMD was $3.48 \mathrm{mg} / \mathrm{L}$, with a sensitivity of $73.64 \%$ and a specificity of $82.35 \%$ (area under curve, 0.792 ). Moreover, the nomogram we constructed indicated that higher level of hs-CRP was an indicator of PMD (c-index $=0.780, P<0.001)$.
\end{abstract}

Conclusions: Our study suggested that hs-CRP might be a useful biomarker for predicting the risk of PMD in patients with PAl.

Keywords: Progressive motor deficit, Penetrating artery infarction, High-sensitivity C-reactive protein, Ischemic stroke

\section{Introduction}

Ischemic stroke is one of the leading causes of mortality and disability worldwide [1-3]. Progressive motor deficit (PMD) is one of the most common neurological deterioration during the acute stage of penetrating artery

\footnotetext{
* Correspondence: zhangyingdong@aliyun.com; qiw_deng@163.com; zhjsh333@126.com

†Yingdong Zhang, Qiwen Deng and Junshan Zhou contributed equally to this work.

${ }^{1}$ Department of Neurology, Nanjing First Hospital, Nanjing Medical University, No. 68 Changle Road, Nanjing 210006, Jiangsu, China

Full list of author information is available at the end of the article
}

infarction (PAI), which accounts for almost $25 \%$ of all ischemic stroke [4]. The incidence of PMD ranges from 13 to $38 \%$ in patients with PAI [5-8]. Several reports have shown that PMD is also associated with poor prognosis of PAI [9-11]. Although several biomarkers [4, 12] have been identified in previous studies, PMD remains insidious and largely unpredictable in clinical practice. Therefore, exploration of the potential mechanisms and measurable biomarkers of PMD among patients with PAI is important.

Neuroinflammatory processes play a fundamental role in the acute stage of ischemic stroke [13-15].

(c) The Author(s). 2019 Open Access This article is distributed under the terms of the Creative Commons Attribution 4.0 International License (http://creativecommons.org/licenses/by/4.0/), which permits unrestricted use, distribution, and 
Several inflammatory biomarkers was reported to be correlated with neurological deterioration in patients with acute ischemic stroke, such as lipoproteinassociated phospholipase A2, [16]. neutrophillymphocyte ratio [17] and so on. Previous studies have revealed that high-sensitivity $\mathrm{C}$-reactive protein (hs-CRP) may act as an inflammatory factor that responds to ischemic stroke $[18,19]$. A high hs-CRP level has been found to show predictive value for poststroke depression [18] and poor outcome [19-22] in ischemic stroke patients. The levels of hs-CRP may be associated with the risk of excessive ischemic stroke independently [23]. However, there are few studies that focused on the clinical value of hs-CRP in patients with PAI. The association between hs-CRP and PMD in ischemic stroke remains unclear. Thus, the purpose of this tricenter observational study was to assess the association between hs-CRP levels at admission and PMD in patients with PAI.

\section{Methods}

\section{Patient selection}

Consecutive patients who presented with symptoms of a lacunar syndrome between January 2015 and September 2018 underwent a standard in-house procedure $[24,25]$ and prospectively recruited from three hospitals. All the patients were treated in the stroke units and received treatments, such as antiplatelet therapy statin therapy and risk factor management. Magnetic resonance (MR), computed tomography, electrocardiogram, echocardiography, carotid ultrasonography and transcranial Doppler, and were performed for assessing the stroke etiology. Eligible patients were included in the present analysis if they met the following criteria.

The inclusion criteria were as follows:

(1) admission within $24 \mathrm{~h}$ of onset with a lacunar syndrome;

(2) patients with penetrating artery infarctions;

(3) age more than 18 years.

The exclusion criteria were as follows:

(1) Patients who had a potential source of cardioembolism or $>50 \%$ stenosis of the extracranial carotid artery;

(2) severe inflammatory diseases or infectious diseases;

(3) lack of motor deficits, such as patients with pure sensory syndrome;

(4) renal failure or hepatic failure;

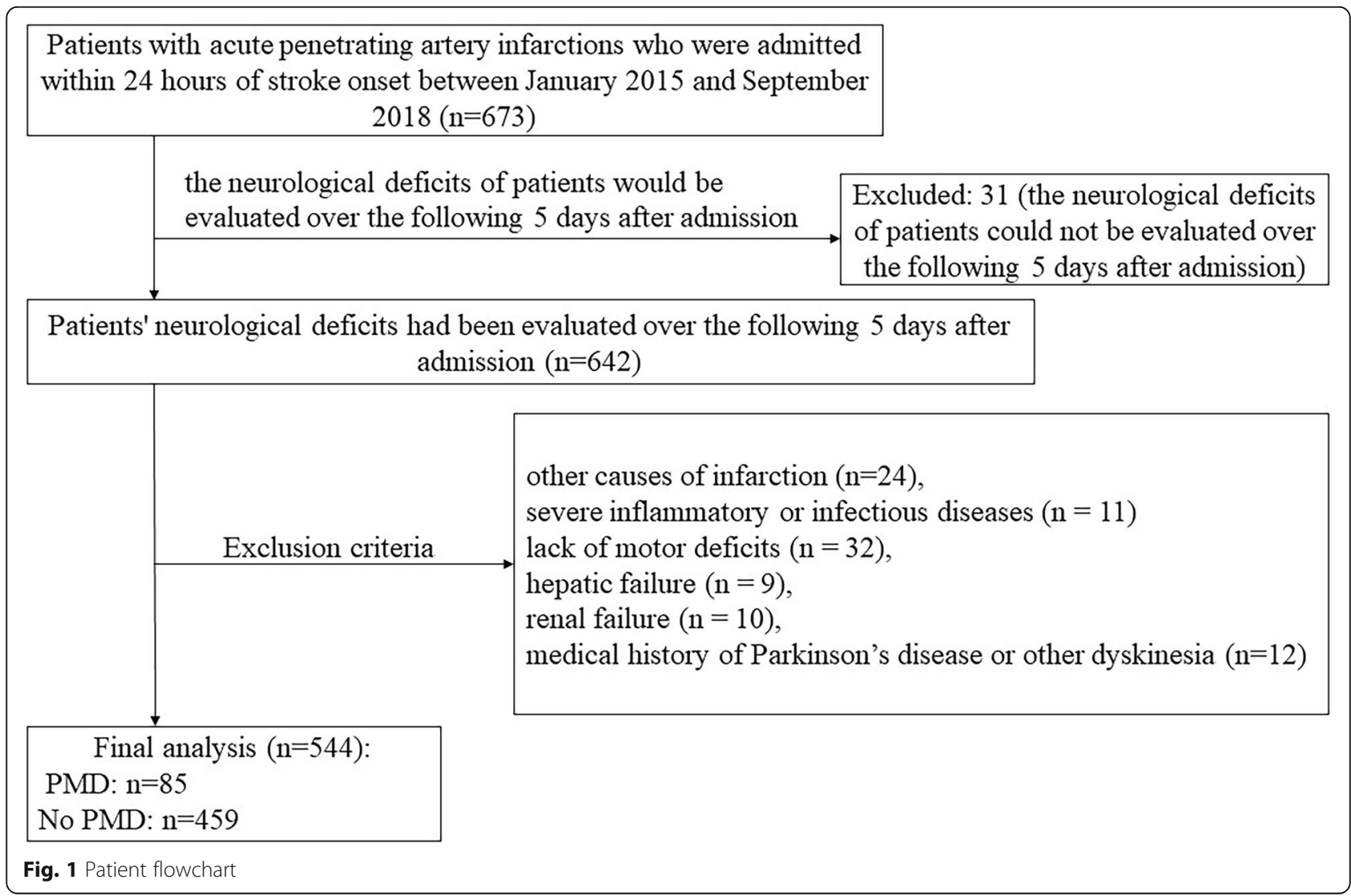


Table 1 Baseline Characteristics of Patients with PMD and Non-PMD

\begin{tabular}{|c|c|c|c|}
\hline Variable & $\operatorname{PMD}(n=85)$ & Non-PMD $(n=459)$ & P \\
\hline \multicolumn{4}{|l|}{ Demographic characteristics } \\
\hline Age, years & $67.8 \pm 11.6$ & $64.9 \pm 11.8$ & 0.038 \\
\hline Male, \% & 60 (70.6) & $327(71.2)$ & 0.903 \\
\hline \multicolumn{4}{|l|}{ Vascular risk factors, \% } \\
\hline Hypertension & $56(65.9)$ & $304(66.2)$ & 0.950 \\
\hline Diabetes mellitus & $44(51.8)$ & $117(25.5)$ & $<0.001$ \\
\hline Dyslipidemia & $15(17.6)$ & $76(16.6)$ & 0.805 \\
\hline Current smoking & $30(35.3)$ & $191(41.6)$ & 0.276 \\
\hline Current drinking & $19(22.4)$ & $143(31.2)$ & 0.197 \\
\hline Previous stroke & $7(8.2)$ & $60(13.1)$ & 0.213 \\
\hline Peripheral artery disease & $4(4.7)$ & $12(2.6)$ & 0.294 \\
\hline Coronary artery disease & $12(14.1)$ & $54(11.8)$ & 0.542 \\
\hline \multicolumn{4}{|l|}{ Clinical data } \\
\hline Previous antiplatelet, \% & $10(11.8)$ & $47(10.2)$ & 0.673 \\
\hline Previous statin, \% & $2(2.4)$ & $14(3.1)$ & 0.727 \\
\hline $\mathrm{SBP}, \mathrm{mmHg}$ & $142.8 \pm 19.8$ & $144.9 \pm 20.8$ & 0.445 \\
\hline $\mathrm{DBP}, \mathrm{mmHg}$ & $84.7 \pm 11.7$ & $86.0 \pm 12.4$ & 0.449 \\
\hline Body mass index, kg/m2 & $24.3 \pm 4.3$ & $24.5 \pm 3.3$ & 0.773 \\
\hline Initial total NIHSS, score & $3(1-4)$ & $2(2-4)$ & 0.728 \\
\hline White matter lesions, \% & 60 (70.6) & $294(64.1)$ & 0.246 \\
\hline Intravenous thrombolysis, \% & $15(17.6)$ & $76(16.6)$ & 0.805 \\
\hline Infra-tentorial infarction, \% & $42(49.4)$ & $244(53.2)$ & 0.525 \\
\hline Supra-tentorial infarction, \% & $43(50.6)$ & $215(46.8)$ & 0.525 \\
\hline \multicolumn{4}{|l|}{ MCA stenosis, \% } \\
\hline 0 & $46(54.1)$ & $261(56.9)$ & 0.639 \\
\hline$\leq 50 \%$ & $35(41.2)$ & $173(37.7)$ & 0.544 \\
\hline$>50 \%$ & $4(4.7)$ & $25(5.4)$ & 0.780 \\
\hline \multicolumn{4}{|l|}{ VBA stenosis, \% } \\
\hline 0 & $40(47.1)$ & $258(56.2)$ & 0.577 \\
\hline$\leq 50 \%$ & $31(36.5)$ & $172(37.5)$ & 0.861 \\
\hline$>50 \%$ & $9(10.6)$ & $30(6.5)$ & 0.183 \\
\hline \multicolumn{4}{|l|}{ Carotid artery atheromatosis, \% } \\
\hline Absence & $39(45.9)$ & $183(39.9)$ & 0.300 \\
\hline Moderate & $39(45.9)$ & $239(52.7)$ & 0.295 \\
\hline Significant & $7(8.2)$ & $37(8.1)$ & 0.957 \\
\hline Silent lacunar infarcts, \% & $42(49.4)$ & $204(44.4)$ & 0.398 \\
\hline OMT, day & $1(1,2)$ & $1(1,2)$ & 0.589 \\
\hline Antibiotic use, \% & $23(27.1)$ & $92(20.0)$ & 0.146 \\
\hline \multicolumn{4}{|l|}{ Laboratory data } \\
\hline Leukocyte number, $10^{\wedge 9}$ & $8.5 \pm 2.4$ & $8.0 \pm 4.3$ & 0.348 \\
\hline $\mathrm{TC}, \mathrm{mmol} / \mathrm{L}$ & $4.4 \pm 1.2$ & $4.5 \pm 1.0$ & 0.338 \\
\hline $\mathrm{TG}, \mathrm{mmol} / \mathrm{L}$ & $2.0 \pm 1.4$ & $1.7 \pm 1.1$ & 0.073 \\
\hline $\mathrm{HDL}, \mathrm{mmol} / \mathrm{L}$ & $1.0 \pm 0.2$ & $1.1 \pm 0.4$ & 0.306 \\
\hline $\mathrm{LDL}, \mathrm{mmol} / \mathrm{L}$ & $2.7 \pm 0.8$ & $2.7 \pm 0.8$ & 0.902 \\
\hline
\end{tabular}


Table 1 Baseline Characteristics of Patients with PMD and Non-PMD (Continued)

\begin{tabular}{llll}
\hline Variable & PMD $(n=85)$ & Non-PMD $(n=459)$ & $P$ \\
\hline FBG, mmol/L & $7.5 \pm 3.5$ & $5.7 \pm 2.1$ & $<0.001$ \\
Glycated hemoglobin, \% & $7.5 \pm 2.4$ & $6.2 \pm 1.3$ & 0.002 \\
Homocysteine, umol/L & $15.6 \pm 8.0$ & $16.1 \pm 8.3$ & 0.519 \\
Hs-CRP, mg/L & $5.9(4.0-9.8)$ & $2.0(1.3-3.8)$ & $<0.001$ \\
\hline
\end{tabular}

Abbreviations: SBP, Systolic blood pressure; DBP, Diastolic blood pressure; National Institutes of Health Stroke Scale; MCA, Middle cerebral artery; VBA, Vertebrobasilar artery; OMT, Onset to the measurement of hs-CRP time; TC, Total cholesterol; TG, Triglyceride; HDL, High density lipoprotein; LDL, Low density lipoprotein; FBG, Fast blood glucose

'Antibiotic use' means 'the antibiotic use during hospitalisation'

(5) medical history of Parkinson's disease or other dyskinesia;

(6) the neurological deficits of patients cannot be evaluated over the following 5 days after admission.

\section{Vascular risk factors}

Hypertension was defined as systolic blood pressure (SBP) $\geq 140 \mathrm{mmHg} /$ or diastolic blood pressure (DBP) $\geq 90 \mathrm{mmHg}$ or use of antihypertensive medication within 2 weeks. SBP and DBP were measured and recorded soon after admission. Diabetes mellitus was defined as either a fasting blood glucose (FBG) level $>7.0 \mathrm{mmol} / \mathrm{L}$ on more than two occasions or the use of an antidiabetic medication. Dyslipidemia was defined as a total cholesterol level $>5.70 \mathrm{mmol} / \mathrm{L}$ and/or a triglyceride level > $5.18 \mathrm{mmol} / \mathrm{L}$ on more than two occasions or the use of lipid-lowering agents. Current smoking and drinking habits were defined as regular smoking and/or drinking at the time of stroke, respectively.

\section{MR imaging}

All participants underwent MR imaging (MRI) and MR angiography (MRA). MRI scans were performed with 3.0-T superconducting magnets. Intracranial artery vessels, including the middle cerebral arteries (MCAs) and vertebrobasilar arteries (VBAs), were assessed by MRA. The severity of stenosis in each intracranial artery was graded based on maximal luminal narrowing according to the following criteria: normal, mild stenosis $(<50 \%)$ and moderate or severe stenosis (50\% or more).

The severity of carotid artery atheromatosis was graded based on the examination results of carotid ultrasonography, which was divided into the following three categories: absence, moderate $(<70 \%)$ and severe $(70 \%$ or more).

\section{Definition of penetrating artery infarction and progressive motor deficit}

PAI was defined as a relevant deep, single hyperintensity in the territory of penetrating arteries $20 \mathrm{~mm}$ or less in diameter on axial slices of an MRI with diffusionweighted imaging (DWI) that corresponded to one of the lacunar syndromes during a patient's presentation in the acute phase.

The evaluation of neurological deficits was conducted using the National Institutes of Health Stroke Scale (NIHSS) score on admission and continued over the following 5 days 2-3 times every day after admission by two certified neurologists blind to clinical information.

PMD was defined as worsening of motor function by $\geq 1$-point on the motor section of NIHSS during the first 5 days after admission [12, 26-28].

White matter lesions were defined as diffuse hyperintensities that were located in the subcortical and periventricular white matter on T2-weighted images and proton density images. Silent lacunar infarcts were defined as penetrating artery occlusions 3 to $15 \mathrm{~mm}$ in diameter in horizontal sections with high intensity on both T2-weighted images and DWI.

\section{Masurement of hs-CRP}

All the blood samples were collected at $7 \mathrm{AM}$ the second day after admission. The levels of hs-CRP were measured with an immunoturbidimetry assay on an Architect c16000 chemistry analyzer (Abbott Diagnostics, Abbott Park, USA).

\section{Statistical analysis}

Statistical analyses were performed with SPSS version 21.0 (SPSS Inc., Chicago, IL, USA). Continuous variables that followed a normal distribution were expressed as the mean \pm standard deviation; other continuous variables that did not follow normal distributions were presented as the median and interquartile range (25th to 75 th percentile). Categorical variables were expressed as constituent ratios. Differences in baseline characteristics among the hs-CRP quartiles were tested using analysis of variance or the Kruskal-Wallis test for continuous variables, and Pearson's chi-square test for categorical variables. We also used binary logistic regression analysis to detect the risk factors for PMD. Multivariable analysis was adjusted for all potential confounders with a statistically significant association at $P<0.05$ in univariate regression analysis. Receiver operating characteristic (ROC) curve analysis was performed to assess the overall 
Table 2 Characteristics of subgroups based on the quartile of hs-CRP

\begin{tabular}{|c|c|c|c|c|c|c|}
\hline Variable & total $(n=544)$ & quartile $1(n=136)$ & quartile $2(n=136)$ & quartile 3 ( $n=136)$ & quartile $4(n=136)$ & $P$ \\
\hline \multicolumn{7}{|l|}{ Demographic characteristics } \\
\hline Age, years & $65.4 \pm 11.8$ & $65.0 \pm 10.3$ & $65.8 \pm 12.0$ & $63.8 \pm 11.6$ & $66.9 \pm 13.0$ & 0.169 \\
\hline Male, \% & $387(71.1)$ & $94(69.1)$ & 103(75.7) & $88(64.7)$ & 102(75.0) & 0.145 \\
\hline \multicolumn{7}{|l|}{ Vascular risk factors, $\%$} \\
\hline Hypertension & $360(66.2)$ & $93(68.4)$ & $90(66.2)$ & $91(66.9)$ & $86(63.2)$ & 0.836 \\
\hline Diabetes mellitus & $161(29.6)$ & $36(26.5)$ & $36(26.5)$ & $40(29.4)$ & $49(36.0)$ & 0.243 \\
\hline Dyslipidemia & $91(16.7)$ & $25(18.4)$ & $21(15.4)$ & $22(16.2)$ & $23(16.9)$ & 0.927 \\
\hline Current smoking & $221(40.6)$ & $55(40.4)$ & $63(46.3)$ & $47(34.6)$ & $56(41.2)$ & 0.270 \\
\hline Current drinking & 162(29.8) & $47(34.6)$ & $44(32.6)$ & $33(24.3)$ & $38(27.9)$ & 0.545 \\
\hline Previous stroke & $67(12.3)$ & $18(13.2)$ & $16(11.8)$ & $22(16.2)$ & $11(8.1)$ & 0.234 \\
\hline Peripheral artery disease & $16(2.9)$ & $3(2.2)$ & $3(2.2)$ & $4(2.9)$ & $6(4.4)$ & 0.672 \\
\hline Coronary artery disease & $66(12.1)$ & $18(13.2)$ & $19(14.0)$ & $15(11.0)$ & $14(10.3)$ & 0.760 \\
\hline \multicolumn{7}{|l|}{ Clinical data } \\
\hline Previous antiplatelet, \% & $57(10.5)$ & $13(9.6)$ & $14(10.3)$ & $17(12.5)$ & $13(9.6)$ & 0.839 \\
\hline Previous statin, \% & $16(2.9)$ & $5(3.7)$ & $4(2.9)$ & $5(3.7)$ & $2(1.5)$ & 0.627 \\
\hline $\mathrm{SBP}, \mathrm{mmHg}$ & $144.6 \pm 20.6$ & $145.0 \pm 19.0$ & $143.1 \pm 21.3$ & $143.6 \pm 20.5$ & $146.8 \pm 21.7$ & 0.465 \\
\hline $\mathrm{DBP}, \mathrm{mmHg}$ & $85.8 \pm 12.3$ & $85.5 \pm 12.3$ & $84.5 \pm 12.5$ & $86.6 \pm 11.8$ & $86.5 \pm 12.7$ & 0.478 \\
\hline Body mass index, kg/m2 & $24.5 \pm 3.5$ & $24.1 \pm 3.7$ & $24.1 \pm 3.0$ & $24.9 \pm 3.2$ & $24.8 \pm 3.9$ & 0.145 \\
\hline Initial totaol NIHSS, score & $2(2-4)$ & $2(1-4)$ & $2(2-4)$ & $2(1-4)$ & $3(2-4)$ & 0.631 \\
\hline White matter lesions, \% & $354(65.1)$ & $94(69.1)$ & $85(62.5)$ & $88(64.7)$ & $87(64.0)$ & 0.692 \\
\hline Intravenous thrombolysis, \% & $91(16.7)$ & $19(14.0)$ & $22(16.2)$ & $24(17.6)$ & $26(19.1)$ & 0.703 \\
\hline PMD, \% & 85 (15.6) & $7(5.1)$ & $3(2.2)$ & $30(22.1)$ & $45(33.1)$ & $<0.001$ \\
\hline \multicolumn{7}{|l|}{ MCA stenosis, \% } \\
\hline 0 & $307(56.4)$ & $83(61.0)$ & $74(54.4)$ & $73(53.7)$ & $77(56.6)$ & 0.611 \\
\hline$\leq 50 \%$ & $208(38.2)$ & $48(35.3)$ & $54(39.7)$ & $54(39.7)$ & $52(38.2)$ & 0.862 \\
\hline$>50 \%$ & $29(5.3)$ & $5(3.7)$ & $8(5.9)$ & $9(6.6)$ & $7(5.1)$ & 0.735 \\
\hline \multicolumn{7}{|l|}{ VBA stenosis, \% } \\
\hline 0 & $302(55.5)$ & $80(58.8)$ & $71(52.2)$ & $73(53.7)$ & $78(57.4)$ & 0.664 \\
\hline$\leq 50 \%$ & $203(37.3)$ & $48(35.3)$ & $56(41.2)$ & $51(37.5)$ & $48(35.3)$ & 0.719 \\
\hline$>50 \%$ & $39(7.2)$ & $8(5.9)$ & $9(6.6)$ & $12(8.8)$ & $10(7.4)$ & 0.809 \\
\hline \multicolumn{7}{|l|}{ Carotid artery atheromatosis, \% } \\
\hline Absence & $222(40.8)$ & $46(33.8)$ & $59(43.4)$ & $62(45.6)$ & $55(40.4)$ & 0.220 \\
\hline Moderate & $278(51.1)$ & $76(55.9)$ & $69(50.7)$ & $62(45.6)$ & $71(52.2)$ & 0.369 \\
\hline Significant & $44(8.1)$ & $14(10.3)$ & $8(5.9)$ & $12(8.8)$ & $10(7.4)$ & 0.577 \\
\hline Silent lacunar infarcts, \% & $246(45.2)$ & $63(46.3)$ & $56(41.2)$ & $62(45.6)$ & $65(47.8)$ & 0.721 \\
\hline OMT, day & $2(1,2)$ & $2(1,2)$ & $2(1,3)$ & $2(1,2)$ & $2(1,2)$ & 0.417 \\
\hline Antibiotic use, $\%$ & $115(21.1)$ & $23(16.9)$ & $32(23.5)$ & $24(17.6)$ & $36(26.5)$ & 0.155 \\
\hline \multicolumn{7}{|l|}{ Laboratory data } \\
\hline Leukocyte number, $10^{\wedge 9}$ & $8.4 \pm 4.1$ & $8.2 \pm 2.7$ & $8.2 \pm 3.0$ & $8.4 \pm 2.6$ & $8.8 \pm 6.6$ & 0.562 \\
\hline $\mathrm{TC}, \mathrm{mmol} / \mathrm{L}$ & $4.5 \pm 1.0$ & $4.3 \pm 1.0$ & $4.5 \pm 1.1$ & $4.5 \pm 1.0$ & $4.4 \pm 1.0$ & 0.313 \\
\hline $\mathrm{TG}, \mathrm{mmol} / \mathrm{L}$ & $1.8 \pm 1.2$ & $1.5 \pm 0.8$ & $1.8 \pm 1.3$ & $1.9 \pm 1.4$ & $1.8 \pm 1.1$ & 0.065 \\
\hline $\mathrm{HDL}, \mathrm{mmol} / \mathrm{L}$ & $1.1 \pm 0.3$ & $1.1 \pm 0.5$ & $1.1 \pm 0.2$ & $1.0 \pm 0.2$ & $1.1 \pm 0.3$ & 0.103 \\
\hline $\mathrm{LDL}, \mathrm{mmol} / \mathrm{L}$ & $2.7 \pm 0.8$ & $2.8 \pm 0.8$ & $2.8 \pm 0.9$ & $2.8 \pm 0.8$ & $2.7 \pm 0.9$ & 0.504 \\
\hline $\mathrm{FBG}, \mathrm{mmol} / \mathrm{L}$ & $6.0 \pm 2.5$ & $5.8 \pm 2.2$ & $5.7 \pm 2.3$ & $6.3 \pm 2.7$ & $6.2 \pm 2.6$ & 0.184 \\
\hline
\end{tabular}


Table 2 Characteristics of subgroups based on the quartile of hs-CRP (Continued)

\begin{tabular}{lllllll}
\hline Variable & total $(n=544)$ & quartile $1(n=136)$ & quartile 2 $(n=136)$ & quartile 3 $(n=136)$ & quartile $4(n=136)$ & $P$ \\
\hline Glycated hemoglobin, \% & $6.4 \pm 1.6$ & $6.3 \pm 1.4$ & $6.3 \pm 1.4$ & $6.6 \pm 1.7$ & $6.6 \pm 1.7$ & 0.082 \\
Homocysteine, umol/L & $16.0 \pm 8.2$ & $14.6 \pm 6.0$ & $16.9 \pm 10.0$ & $15.8 \pm 7.5$ & $16.9 \pm 8.7$ & 0.076 \\
\hline
\end{tabular}

Abbreviations: SBP, Systolic blood pressure; DBP, Diastolic blood pressure; National Institutes of Health Stroke Scale; MCA, Middle cerebral artery; VBA, Vertebrobasilar artery; OMT, Onset to the measurement of hs-CRP time;TC, Total cholesterol; TG, Triglyceride; HDL, High density lipoprotein; LDL, Low density lipoprotein; FBG, Fast blood glucose

'Antibiotic use' means 'the antibiotic use during hospitalisation'

discriminative ability of hs-CRP to predict PMD and to establish optimal cutoff points at which the sum of the specificity and sensitivity was the highest. A MedCalc 15.6.0 (MedCalc Software Acacialaan 22, B-8400 Ostend, Belgium) packet program was used to obtain the ROC curve and to analyze specify and sensitivity of hs-CRP for the exitus status. In addition, a nomogram based on the independent predictors was constructed by $\mathrm{R}$ software with the package rms. The predictive capacity of the nomogram was determined by Harrell's c-index. A two-tailed value of $P<0.05$ was considered significant.

\section{Results}

From January 2015 to September 2018, 642 patients with acute PAI who were admitted within $24 \mathrm{~h}$ of stroke onset were screened for 5 days in this study (Fig. 1). Thirtyone patients' neurological deficits could not be evaluated over the following 5 days after admission. Sixty-eight patients were excluded for the following reasons: other causes of infarction $(n=24)$, severe inflammatory or infectious diseases $(n=11)$, lack of motor deficits, such as patients with pure sensory syndrome $(n=32)$, hepatic failure $(n=9)$, renal failure $(n=10)$, medical history of Parkinson's disease or other dyskinesia $(n=12)$. A total of 544 subjects ( 387 men; mean age, $65.4 \pm 11.8$ years) were included in the final analysis (Fig. 1). PMD was observed in 85 patients (15.6\%).

A comparison of the baseline characteristics of the groups with and without PMD are presented in Table 1. The PMD group had significantly higher levels of hsCRP than the non-PMD group (5.9 [4.0, 19.8] versus 2.0 [1.3, 3.8], $P<0.001)$.

The median hs-CRP was $6.46 \mathrm{mg} / \mathrm{L}$, with quartile levels as follows: $0.18 \mathrm{mg} / \mathrm{L}$ to $1.28 \mathrm{mg} / \mathrm{L}$ (first quartile); $1.28 \mathrm{mg} / \mathrm{L}$ to $2.33 \mathrm{mg} / \mathrm{L}$ (second quartile); $2.35 \mathrm{mg} / \mathrm{L}$ to $5.19 \mathrm{mg} / \mathrm{L}$ (third quartile); $5.26 \mathrm{mg} / \mathrm{L}$ to $293.00 \mathrm{mg} / \mathrm{L}$ (fourth quartile). Baseline characteristics of the study population according to hs-CRP quartiles are provided in Table 2. The results showed that increased hs-CRP was significantly related to PMD in patients with acute PAI $(P=0.001)$.

Table 3 shows the results of logistic regression analysis for risk factors of PMD. Univariable logistic regression analysis was used to investigate the significance of variables on predicting PMD in patients with PAI.
Univariate logistic regression analyses demonstrated that the third quartile of hs-CRP, the fourth quartile of hsCRP, age, diabetes mellitus, and levels of FBG and glycated hemoglobin were associated with PMD $(P<0.05)$. Significant predictors in the univariable analysis were included in a multivariable regression model to determine independent predictors. After adjusting for all potential confounders, age, glycated hemoglobin level and the third quartile and fourth quartile of hs-CRP (first quartile used as the reference value) were identified as independent predictors for PMD.

To further assess the clinical significance of hs-CRP in PMD, we performed a ROC curve analysis as depicted in Fig. 2. We observed that the area under curve (AUC) of hs-CRP was 0.792 (95\% CI, 0.756-0.826) with the ability to discriminate PMD. The optimal cutoff value for hsCRP as a predictor of PMD was determined to be 3.48 $\mathrm{mg} / \mathrm{L}$ in the ROC curve analysis, yielding the largest Youden's index value (a sensitivity of $73.64 \%$ and a specificity of $82.35 \%$ ). The AUC was 0.792 (95\% CI, $0.756-$ 0.826).

The nomogram is shown in Fig. 3, and the concordance index of this model was $0.780(P<0.001)$. These findings were similar to those obtained previously in the multivariate logistic models.

\section{Discussion}

Our observational study revealed that elevated plasma levels of hs-CRP remained an independent predictor for PMD in patients with PAI after adjusting for age, diabetes mellitus and other possible confounders. In general, a biomarker with $0.7<$ area under the curve $<0.9$ indicates a moderate diagnostic value. High hs-CRP levels $(>3.48 \mathrm{mg} / \mathrm{L})$ have a moderate ability to diagnose PMD. Furthermore, our constructed nomogram indicated that higher hs-CRP was an indicator of PMD. Thus, the hs-CRP value at admission represented a readily available predictor for PMD in patients with PAI. The serum biomarker, hs-CRP at admission, is able to identify earlier than the standard clinical and imaging assessment. Furthermore, our study also showed that age and glycated hemoglobin were predictors of PMD, which was consistent with the findings of other studies [19, 28]. 
Table 3 Logistic regression analysis for risk factors with PMD

\begin{tabular}{|c|c|c|c|c|}
\hline Variable & Unadjusted OR (95\%Cl) & $P$ & Adjusted OR (95\%Cl) & $P$ \\
\hline \multicolumn{5}{|l|}{ Demographic characteristics } \\
\hline Age, years & $1.021(1.001-1.042)$ & 0.038 & $1.025(1.001-1.048)$ & 0.048 \\
\hline Male & $0.969(0.583-1.611)$ & 0.903 & & \\
\hline \multicolumn{5}{|l|}{ Vascular risk factors } \\
\hline Hypertension & $0.985(0.604-1.604)$ & 0.950 & & \\
\hline Diabetes mellitus & $3.137(1.952-5.041)$ & 0.001 & 1.757 (0.934-3.304) & 0.080 \\
\hline Dyslipidemia & $1.080(0.587-1.987)$ & 0.805 & & \\
\hline Current smoking & $0.765(0.473-1.239)$ & 0.227 & & \\
\hline Current drinking & $0.707(0.420-1.191)$ & 0.192 & & \\
\hline Previous stroke & $0.597(0.263-1.354)$ & 0.217 & & \\
\hline \multicolumn{5}{|l|}{ Clinical data } \\
\hline Previous antiplatelet & $1.169(0.566-2.415)$ & 0.674 & & \\
\hline Previous statin & $0.766(0.171-3.433)$ & 0.728 & & \\
\hline SBP & $0.995(0.983-1.006)$ & 0.374 & & \\
\hline DBP & $0.992(0.973-1.011)$ & 0.398 & & \\
\hline Body mass index & $0.985(0.913-1.063)$ & 0.694 & & \\
\hline Initial total NIHSS & $1.018(0.941-1.103)$ & 0.653 & & \\
\hline White matter lesions & $1.347(0.814-2.230)$ & 0.247 & & \\
\hline Intravenous thrombolysis & $1.080(0.587-1.987)$ & 0.805 & & \\
\hline Infra-tentorial infarction & $1.162(0.731-1.846)$ & 0.525 & & \\
\hline Silent lacunar infarcts & $1.221(0.768-1.941)$ & 0.398 & & \\
\hline \multicolumn{5}{|l|}{ MCA stenosis } \\
\hline 0 & $1.118(0.702-1.779)$ & 0.639 & & \\
\hline$\leq 50 \%$ & $1.157(0.722-1.854)$ & 0.544 & & \\
\hline$>50 \%$ & $0.926(0.539-1.590)$ & 0.780 & & \\
\hline \multicolumn{5}{|l|}{ VBA stenosis } \\
\hline 0 & $1.141(0.717-1.815)$ & 0.578 & & \\
\hline$\leq 50 \%$ & $0.958(0.593-1.549)$ & 0.861 & & \\
\hline$>50 \%$ & $1.301(0.879-1.926)$ & 0.188 & & \\
\hline Antibiotic use & $1.480(0.871-2.515)$ & 0.147 & & \\
\hline \multicolumn{5}{|l|}{ Hs-CRP distribution } \\
\hline Quartile 1 & Reference & & Reference & \\
\hline Quartile 2 & $0.416(0.105-1.642)$ & 0.211 & $0.468(0.110-1.981)$ & 0.302 \\
\hline Quartile 3 & $5.216(2.203-12.349)$ & 0.001 & 5.191(1.974-13.649) & 0.002 \\
\hline Quartile 4 & 9.113 (3.933-21.116) & 0.001 & 9.786 (3.819-25.075) & 0.001 \\
\hline \multicolumn{5}{|l|}{ Laboratory data } \\
\hline Leukocyte number, $10^{\wedge 9}$ & $0.957(0.879-1.043)$ & 0.320 & & \\
\hline $\mathrm{TC}, \mathrm{mmol} / \mathrm{L}$ & $0.930(0.743-1.164)$ & 0.528 & & \\
\hline $\mathrm{TG}, \mathrm{mmol} / \mathrm{L}$ & $1.169(0.983-1.391)$ & 0.077 & & \\
\hline $\mathrm{HDL}, \mathrm{mmol} /$ & $0.548(0.220-1.365)$ & 0.196 & & \\
\hline $\mathrm{LDL}, \mathrm{mmol} / \mathrm{L}$ & $0.876(0.657-1.169)$ & 0.370 & & \\
\hline $\mathrm{FBG}, \mathrm{mmol} / \mathrm{L}$ & $1.254(1.152-1.364)$ & 0.001 & $1.067(0.934-1.218)$ & 0.340 \\
\hline Glycated hemoglobin, \% & $1.495(1.313-1.701)$ & 0.001 & $1.351(1.095-1.668)$ & 0.005 \\
\hline Homocysteine, umol/L & $0.992(0.960-1.026)$ & 0.646 & & \\
\hline
\end{tabular}




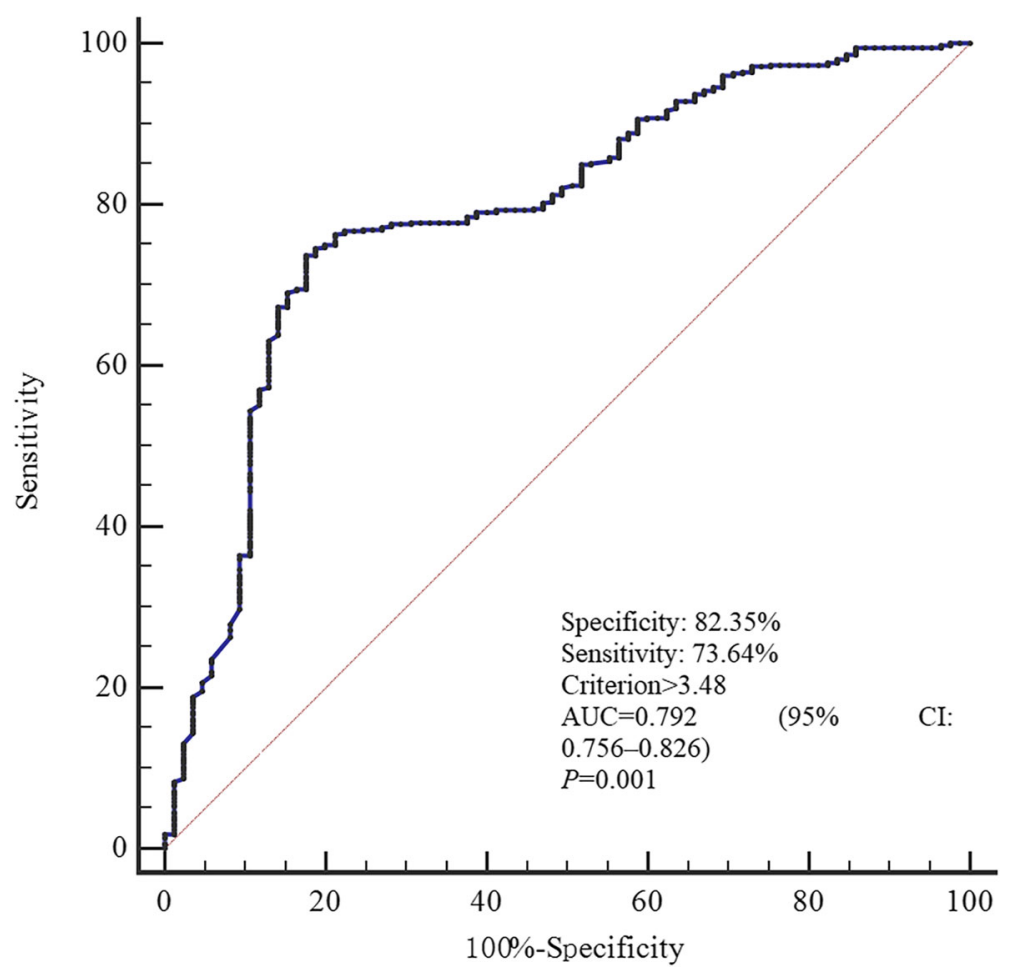

Fig. 2 Receiver operating characteristic (ROC) curve for the value of hs-CRP to predict PMD

The influence of hs-CRP on ischemic stroke has been well established, and hs-CRP has been reported as a predictor of disease severity, prognosis and mortality in patients with ischemic stroke $[19,29]$. Furthermore, high plasma hs-CRP levels are associated with clinical complications following acute ischemic stroke $[18,30]$ PMD, which may result in severe morbidity, commonly occurs in patients with PAI during the acute stage. This is the first study to explore the relationship between hs-CRP and PMD in patients with penetrating artery ischemic stroke. PMD was revealed to have an incidence of $15.6 \%$ in this trial, which was in accordance with a previous study $[19,28]$. Moreover, in a previous case presentation, the patient with PMD was found to be complicated by depressive disorder and anxiety disorder [31]. Our observational study showed the predictive value of hs-CRP for the occurrence of PMD in patients with PAI. It provides a biomarker for early detection of PMD.

Hs-CRP, a systemic inflammatory marker, is produced in large amounts by hepatocytes in response to IL- 1 , IL6 and TNF- $\alpha$ [32, 33]. Inflammatory responses play a vital role in ischemic stroke $[13-15,34,35]$. The

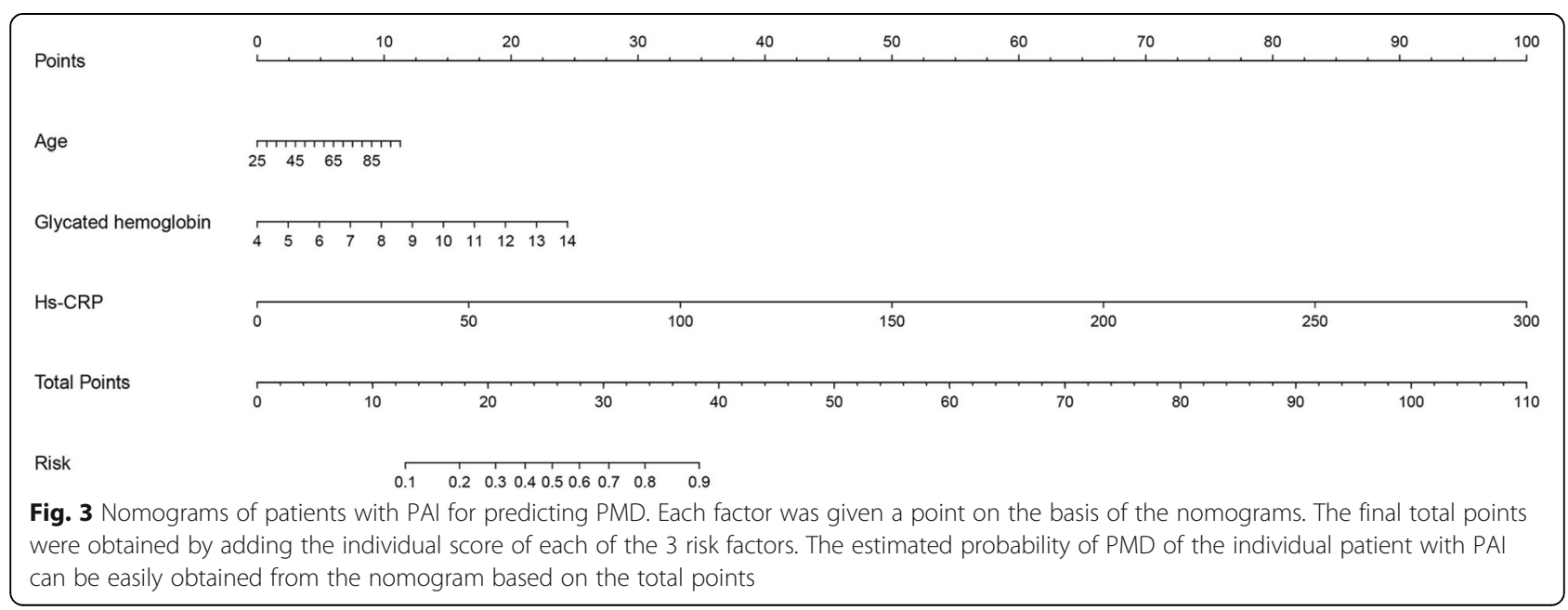


ischemic tissues release inflammatory cytokines and chemokines, among which hs-CRP is one of the mediators of ischemic brain injury. Cytokines and inflammatory factors lead to neuronal necrosis, endothelial permeability of vessels and blood-brain barrier disruption, resulting in the mortality of neurons and induction of apoptosis [34, 35]. Hence, PMD is believed to result from biochemical abnormalities such as inflammation.

However, several limitations should be considered. First, the sample size of our study was relatively small, and larger cohorts of subjects are needed. Second, we did not investigate dynamic changes in hs-CRP; the combination of baseline and dynamic hs-CRP may provide a more objective and comprehensive way to predict PMD in PAI patients. Third, we only performed digital subtraction angiography (DSA) for a limited number of patients. The severity of stenosis in each intracranial artery could only be assessed by by MRA instead of DSA, which may not be the most precise. Moreover, we did not perform the plaque imaging to evaluate carotid artery atheromatosis, which might be a factor that is related to inflammation process. Finally, many factors that might affect inflammatory markers were not taken into consideration.

\section{Conclusion}

In summary, based on the conclusion of our study, hsCRP levels are able to serve as a useful noninvasive biomarker for the assessment of PMD. The association between hs-CR and PMD should be considered in the management of PAI.

\section{Abbreviations}

AUC: Area under curve; DWI: Diffusion-weighted imaging; FBG: Fasting blood glucose; hs-CRP: High-sensitivity C-reactive protein; MCA: Middle cerebral artery; MR: Magnetic resonance; MRA: Magnetic resonance angiography; MRI: Magnetic resonance imaging; NIHSS: National Institutes of Health Stroke Scale; PAl: Penetrating artery infarction; PMD: Progressive motor deficit; ROC: Receiver operating characteristic; VBA: Vertebrobasilar arteries

\section{Acknowledgements}

Not applicable.

\section{Authors' contributions}

Data curation, $T H, W C, Y G$ and $X Z$; Formal analysis, $X Z$; Investigation, $Y L$ and MW; Methodology, TJ, ML and $Y Z$; Writing original draft, $P G$; Writing review and editing, QD and JZ. All authors read and approved the final manuscript.

\section{Funding}

This work was supported by the Major Program of Nanjing Medical Science and Technology Development Foundation (ZDX16002), the Key Program of Nanjing Medical Science and Technology Development Foundation (ZKX16050) and the Ordinary Program of Nanjing Medical Science and Technology Development Foundation (YKK16142). The the role of the funding bodies is data collection and document retrieval.

\section{Availability of data and materials}

The datasets used and/or analysed during the current study are available from the corresponding author on reasonable request.

\section{Ethics approval and consent to participate}

Patients were prospectively recruited from Nanjing First Hospital, the Second Affiliated Hospital of Nanjing University of Chinese Medicine and Nantong Third People's Hospital. Eligible patients were included in the present analysis if they met the following criteria. Protocols were approved by the Ethical Committee of Nanjing First Hospital, the Ethical Committee of the Second Affiliated Hospital of Nanjing University of Chinese Medicine and the Ethical Committee of Nantong Third People's Hospital. Written Informed consent for this study was obtained from all patients or their family members.

\section{Consent for publication}

Not Applicable.

\section{Competing interests}

The authors declare that they have no competing interests.

\section{Author details}

${ }^{1}$ Department of Neurology, Nanjing First Hospital, Nanjing Medical University, No. 68 Changle Road, Nanjing 210006, Jiangsu, China. ${ }^{2}$ Department of Critical Care Medicine, Nanjing First Hospital, Nanjing Medical University, No.68 Changle Road, Nanjing 210006, Jiangsu, China. ${ }^{3}$ Department of Gerontology, Nantong Third Peoples Hospital, Nantong University, 60 Mid-Youth Road, Nantong 226006, Jiangsu, China. ${ }^{4}$ Department of Neurology, Second Affiliated Hospital of Nanjing University of Chinese Medicine, Nanjing 210002, Jiangsu, China.

Received: 23 July 2019 Accepted: 21 November 2019

Published online: 29 December 2019

\section{References}

1. Feigin $\mathrm{VL}$, Forouzanfar MH, Krishnamurthi $\mathrm{R}$, Mensah GA, Connor M, Bennett DA, Moran AE, Sacco RL, Anderson L, Truelsen T, O'Donnell M, Venketasubramanian N, Barker-Collo S, Lawes CM, Wang W, Shinohara Y, Witt E, Ezzati M, Naghavi M, Murray C, Global Burden of Diseases, Injuries, and Risk Factors Study 2010 (GBD 2010) and the GBD Stroke Experts Group. Global and regional burden of stroke during 1990-2010: findings from the Global Burden of Disease Study 2010. Lancet. 2014;383:245-54.

2. Towfighi A, Saver JL. Stroke declines from third to fourth leading cause of death in the United States: historical perspective and challenges ahead. Stroke. 2011:42:2351-5.

3. Deng QW, Li S, Wang H, Lei L, Zhang HQ, Gu ZT, et al. The short-term prognostic value of the triglyceride-to-high-density lipoprotein cholesterol ratio in acute ischemic stroke. Aging Dis. 2018;9(3):498-506.

4. Kawano T, Miyashita K, Takeuchi M, Nagakane Y, Yamamoto Y, Kamiyama K, et al. Blood biomarkers associated with neurological deterioration in patients with acute penetrating artery territory infarction: a multicenter prospective observational study. Int J Stroke. 2018;13(2):207-16.

5. Yu YP, Tan L. The infarct shape predicts progressive motor deficits in patients with acute lacunae-sized infarctions in the perforating arterial territory. Intern Med. 2015;54:2999-3004.

6. Oh S, Bang OY, Chung CS, Lee KH, Chang WH, Kim GM. Topographic location of acute pontine infarction is associated with the development of progressive motor deficits. Stroke. 2012;43:708-13.

7. Kim YB, Moon HS, Suh BC, Park KY, Lee YT, Chung PW. Topographic patterns and stroke subtypes according to progressive motor deficits in lacunar syndrome. J Stroke Cerebrovasc Dis. 2011;20:352-6.

8. Serena J, Leira R, Castillo J, Pumar JM, Castellanos M, Dávalos A Neurological deterioration in acute lacunar infarctions: the role of excitatory and inhibitory neurotransmitters. Stroke. 2001;32:1154-61.

9. Li JB, Cheng RD, Zhou L, Wen WS, Zhu GY, Tian L, et al. What drives progressive motor deficits in patients with acute pontine infarction? Neural Regen Res. 2015;10(3):501-4

10. Dávalos A, Cendra E, Teruel J, Martinez M, Genís D. Deteriorating ischemic stroke: risk factors and prognosis. Neurology. 1990;40:1865-9.

11. Erro ME, Gállego J, Herrera M, Bermejo B. Isolated pontine infarcts: etiopathogenic mechanisms. Eur J Neurol. 2005:12:984-8.

12. Yamamoto Y, Ohara T, Hamanaka M, Hosomi A, Tamura A, Akiguchi I, et al. Predictive factors for progressive motor deficits in penetrating artery infarctions in two different arterial territories. J Neurol Sci. 2010;288:170-4. 
13. Kim JY, Park J, Chang JY, Kim SH, Lee JE. Inflammation after ischemic stroke: the role of leukocytes and glial cells. Exp Neurobiol. 2016;25:241-51.

14. Wu D, Zhi X, Duan $Y$, Zhang $M, A n$ H, Wei W, et al. Inflammatory cytokines are involved in dihydrocapsaicin $(\mathrm{DHC})$ and regional cooling infusion ( $\mathrm{RCl}$ )induced neuroprotection in ischemic rat. Brain Res. 1710;2019:173-80.

15. Anrather J, ladecola C. Inflammation and stroke: An overview. Neurotherapeutics. 2016;13:661-70.

16. Wang $Y$, Hu S, Ren L, Lei Z, Lan T, Cai J, et al. Lp-PLA2 as a risk factor of early neurological deterioration in acute ischemic stroke with TOAST type of large arterial atherosclerosis. Neurol Res. 2019;41(1):1-8.

17. Gong P, Xie Y, Jiang T, Liu Y, Wang M, Sun H, et al. Neutrophil-lymphocyte ratio predicts post-thrombolysis early neurological deterioration in acute ischemic stroke patients. Brain Behav. 2019;9(10):e01426.

18. Tang CZ, Zhang YL, Wang WS, Li WG, Shi JP. Serum levels of high-sensitivity C-reactive protein at admission are more strongly associated with Poststroke depression in acute ischemic stroke than Homocysteine levels. Mol Neurobiol. 2016;53(4):2152-60.

19. Cai Z, He W, Zhuang FJ, Chen Y. The role of high high-sensitivity C-reactive protein levels at admission on poor prognosis after acute ischemic stroke. Int J Neurosci. 2019;129:423-9.

20. Wu X, Liu G, Zhou W, Ou A, Liu X, Wang Y, et al. Outcome prediction for patients with anterior circulation acute ischemic stroke following endovascular treatment: a single-center study. Exp Ther Med. 2019;18(5): 3869-76.

21. Gao Y, Liu J, Wang W, Gao C, Yu C, Liu S, et al. An elevated high-sensitivity C-reactive protein level is associated with unfavorable functional outcomes of Small-artery occlusion in patients without diabetes. Eur Neurol. 2017; 78(1-2):48-55.

22. Hou D, Liu J, Feng R, Gao Y, Wang Y, Wu J. The role of high-sensitivity Creactive protein levels in functional outcomes in patients with large-artery atherosclerosis and small-artery occlusion. Neurol Res. 2017;39(11):981-7.

23. Zhou Y, Han W, Gong D, Man C, Fan Y. Hs-CRP in stroke: a meta-analysis. Clin Chim Acta. 2016;453:21-7.

24. Powers WJ, Derdeyn CP, Biller J, Coffey CS, Hoh BL, Jauch EC, et al. 2015 American Heart Association/American Stroke Association focused update of the 2013 guidelines for the early Management of Patients with acute ischemic stroke regarding endovascular treatment: a guideline for healthcare professionals from the American Heart Association/American Stroke Association. Stroke. 2015;46:3020-35.

25. Powers WJ, Rabinstein AA, Ackerson T, Adeoye OM, Bambakidis NC, Becker K, et al. 2018 guidelines for the early Management of Patients with acute ischemic stroke: a guideline for healthcare professionals from the American Heart Association/American Stroke Association. Stroke. 2018;49:e46-99.

26. Kim SK, Song P, Hong JM, Pak CY, Chung CS, Lee KH, et al. Prediction of progressive motor deficits in patients with deep subcortical infarction. Cerebrovasc Dis. 2008;25:297-303.

27. Audebert HJ, Pellkofer TS, Wimmer ML, Haberl RL. Progression in lacunar stroke is related to elevated acute phase parameters. Eur Neurol. 2004;5: 125-31.

28. Kim YS, Lee KY, Koh SH, Park CY, Kim HY, Lee YJ, et al. The role of matrix metalloproteinase 9 in early neurological worsening of acute lacunar infarction. Eur Neurol. 2006;55:11-5.

29. Yu H, Huang Y, Chen X, Nie W, Wang Y, Jiao Y, et al. High-sensitivity Creactive protein in stroke patients - the importance in consideration of influence of multiple factors in the predictability for disease severity and death. J Clin Neurosci. 2017;36:12-9.

30. Martin AJ, Price Cl. A Systematic Review and Meta-Analysis of Molecular Biomarkers Associated with Early Neurological Deterioration Following Acute Stroke. Cerebrovasc Dis. 2018;46:230-41.

31. Small G. Progressive motor deficits and psychosis after stroke: a case presentation. J Neurosci Nurs. 2016;48(2):68-70.

32. Lakhan SE, Kirchgessner A, Hofer M. Inflammatory mechanisms in ischemic stroke: therapeutic approaches. J Transl Med. 2009;7:97.

33. Butterweck V, Prinz S, Schwaninger M. The role of interleukin-6 in stressinduced hyperthermia and emotional behaviour in mice. Behav Brain Res. 2003; 144:49-56

34. Esenwa CC, Elkind MS. Inflammatory risk factors, biomarkers and associated therapy in schaemic stroke. Nat Rev Neurol. 2016;12:594-604.

35. Lucas SM, Rothwell NJ, Gibson RM. The role of inflammation in CNS injury and disease. Br J Pharmacol. 2009;147:S232-40.

\section{Publisher's Note}

Springer Nature remains neutral with regard to jurisdictional claims in published maps and institutional affiliations.
Ready to submit your research? Choose BMC and benefit from:

- fast, convenient online submission

- thorough peer review by experienced researchers in your field

- rapid publication on acceptance

- support for research data, including large and complex data types

- gold Open Access which fosters wider collaboration and increased citations

- maximum visibility for your research: over $100 \mathrm{M}$ website views per year

At BMC, research is always in progress.

Learn more biomedcentral.com/submissions 